\title{
An Information Technology Call to Action to Support Healthy Homes
}

\author{
Kevin G Croke, PhD (Emeritus Professor, School of Public Health) ${ }^{1}$, Edward K. Mensah, PhD \\ (Associate Professor) ${ }^{1}$ \\ ${ }^{1}$ Health Policy and Administration Division \\ School of Public Health \\ University of Illinois at Chicago
}

1603 West Taylor Street (M/C 923)

Chicago Illinois, 60612

DOI: 10.5210/ojphi.v11i2.10247

Copyright @2019 the author(s)

This is an Open Access article. Authors own copyright of their articles appearing in the Online Journal of Public Health Informatics.

Readers may copy articles without permission of the copyright owner(s), as long as the author and OJPHI are acknowledged in the copy and the copy is used for educational, not-for-profit purposes.

Advances in information technology over the last decade offer the opportunity to advance the goals of public health advocates to provide safer and healthier home environments. A call to action in public health informatics is needed to realize the benefits of information technology to support healthy home objectives.

\section{Surgeon General Healthy Homes Call to Action}

In 2009, the Surgeon General issued a report, "A Call to Action," to promote healthy homes. Although there have been tremendous efforts to promote healthy home environments since that time, regrettably, many of the recommendations of that report regarding the need for action are still valid. The report made the case that unhealthy conditions in homes and apartments are a major public health hazard. Mold and poor ventilation are responsible for $20 \%$ of asthma cases. Radon in homes is the second leading cause of lung cancer. Fires in homes cause 12,000 injuries and 2,500 deaths per year. According to a report by the Centers for Disease Control and Prevention carbon monoxide exposure contributes to approximately 450 deaths and more than 15,000 emergency department visits annually. Sixty-four percent of the exposures occurred in homes. Research shows that carbon monoxide exposures increase during winter; and a high proportion of the increase is attributed to the following causes: the use of home heating systems, increased use of gasoline-powered generators, indoor use of charcoal grills, portable stoves, and space heaters. Over 240,000 children live in dwellings having unsafe exposure to lead. The link between home hazards and public health is indisputable. 
Advances in the development of mobile applications, cloud-based computing, online education, and artificial intelligence if applied to the management of healthy home inspection programs could have profound beneficial effects in responding to the Surgeon General's call to action.

\section{Dimensions of Information Technology Support}

Mobile applications using cell phones and tablets transform the collection of home inspection data from the isolated recording of housing conditions to a situation in which reliable data can be collected in a consistent manner. Due to public agency budget constraints and the present lack of Information technology support, the goal of establishing a continuity of care related to building conditions based on periodic inspections is difficult to achieve.

Cloud-based data storage allows the analysis of home inspection data from a variety of sources in an efficient and cost-effective manner. Of equal importance, advances in information technology allow for progress to be made in developing a profile and prioritization of home hazards. Geographic information systems showing areas needing remedial action in public housing could help target resources for inspection. Decision support systems that generate actionable alerts from residents to inspectors to trigger priority inspections may also be useful.

The level of tenant involvement in healthy homes programs can increase the value of information technology support. For example, organizations, such as the Metropolitan Tenant Organization, receive thousands of calls per year from tenants many of which regard healthy housing problems. These inquiries must presently be answered by personnel manning phones. Artificial intelligence applications would now allow many of these inquiries to be handled by computerized chatbots.

The wide variety of hazards would underscore the need to involve community and residents in healthy home programs that go beyond simply code enforcement efforts. A "Healthy Homes for Community Health Workers" report developed by the National Center for Healthy Housing lists the control of dust mites, pest control, operational fire alarms, household chemical hazards, heating and ventilating conditions, carbon monoxide alarms, safety from falls, lead poisoning, asbestos, and radon among the hazards of which residents should be aware. The use of mobile application text based communication vastly increases the ability to customize advice on specific inspected health hazard problems to targeted residents and homeowners.

Unfortunately, many of the advantages of the employment of Information technology have yet to be realized in the existing pen and paper, or even tablet-based isolated home inspection data collection systems.

\section{A Call to Information Technology Action to Support Healthy Homes}

At present, there are a number of Information technology support systems for home and building inspections, but no clear dominant application. Standardized protocols are needed for building inspection activities that can be employed in information inspection applications. Little analysis of the effectiveness of information technology in municipal, public housing, or tenant organizations exists. In blunt terms, not enough well-structured experience in the use of information technology support exists to reliably guide in future information technology development. As a general call to action to support healthy homes, the development and funding 
of well-structured pilot projects ideally involving universities, public housing agencies, local communities, and municipalities in partnerships should be initiated to assess alternative development paths.

One of the most beneficial areas to introduce pilot programs relates to the Housing and Urban Development (HUD) inspection programs. Over two million people live in HUD supported housing. In 2019 the US Government Accounting Office sent a report to Congress which was critical of the HUD Real Estate Assessment Center (REAC) operations relating to their physical inspection program. The report listed a number of weaknesses in the program including misrepresentation of housing conditions, inadequate training of inspectors and a lack of quality control in assuring housing deficiencies are corrected. Many of these problems could at least in part be corrected by the support of information technology. Initiatives in information technology application by a program as large as HUD REAC could pave the way for adoption by smaller public health agencies and municipalities.

The journal would welcome comments, suggestions or articles regarding how to advance the practice of healthy home informatics.

\section{References}

U.S. Government Accountability Office. (GAO). (2019). GAO-19-254. Real Estate Assessment Center: HUD Should Improve Physical Inspection Process and Oversight of Inspectors. Retrieved March 21, 2019 from https://www.gao.gov/products/GAO-19-254

National Center for Healthy Housing - https://nchh.org/resourcelibrary/HH_Coalition_Case_Statement_FINAL_2015.06.pdf - National Safe and Healthy Housing Coalition, 2015 Case Statement, June 2015.

U.S. Department of Health and Human Services, (HHS). (2009). The Surgeon General's Call to Action To Promote Healthy Homes. U.S. Department of Health and Human Services, Office of the Surgeon General. doi: NBK44192

Centers for Disease Control and Prevention, (CDC). (2005). Annual smoking-attributable mortality, years of potential life lost, and productivity losses--united states, 1997-2001. MMWR.Morbidity and Mortality Weekly Report, 54(25), 625-628. doi:mm5425a1 [pii]

Centers for Disease Control and Prevention, (CDC). (2005). Unintentional non-fire-related carbon monoxide exposures--united states, 2001-2003. MMWR.Morbidity and Mortality Weekly Report, 54(2), 36-39. doi:mm5402a2 [pii]

Daley, W. R., Smith, A., Paz-Argandona, E., Malilay, J., \& McGeehin, M. (2000). An outbreak of carbon monoxide poisoning after a major ice storm in Maine. The Journal of Emergency Medicine, 18(1), 87-93. doi:S0736-4679(99)00184-5 [pii] 